\title{
प्रमुख ललित निबन्धकारों की व्यंग्य दृष्टि
}

रमेश टण्डन

\author{
सारांश
}

ऐसे प्रमुख निबन्धकार जिन्होंने ललित निबन्ध एवं व्यंग्य निबन्ध दोनों लिखे, को उनके निबन्धगत लक्षण एवं विषय-क्षेत्र की दृष्टि से यहाँ अध्ययन में लिया गया है। ये निबन्धकार, व्यंग्यकार कम एवं ललित निबन्धकार अधिक कहे जाते हैं। विवेच्य निबन्धकारों में हजारी प्रसाद द्विवेदी, जैनेन्द्र कुमार, शांतिप्रिय द्विवेदी, गुलाबराय, माखनलाल चतुर्वेदी, विद्यानिवास मिश्र, दयाकृष्ण विजयवर्गीय 'विजय', एन. ई. विश्वनाथ अय्यर, निशांतकेतु आदि लेखकों के नाम आदरणीय है। विवेचन से स्पष्ट है कि भाषा की स्निग्धता एवं अनुभूति की विशदता तथा गंभीर व व्यापक दृष्टिकोण से ललित निबन्धों का विषय-विवेचन होता है, इसके विपरीत व्यंग्य निबन्धों में सरल भाषा में सच्चाई की धरातल पर छोटी-सी-छोटी मान्यताओं को परखा जाता है, व्यंग्य विसंगतियों को कुरेदा जाता है। ललित निबन्धों में समीक्षा के गाम्भीर्य, व्यापक दृष्टिकोण, गम्भीर विश्लेषण, गहन अध्ययन एवं शोधपरक दृष्टि की आवश्यकता होती है; पर आस-पास के परिवेश में व्याप्त विषमताएँ, विसंगतियाँ सहज ही व्यंग्य को जन्म दे डालती हैं।

कूट शब्द - ललित निबन्धकार एवं व्यंग्य दृष्टि

हजारी प्रसाद द्विवेदी जी ने भारतीय और पश्चात्त्य निबन्ध प्रणालियों की विविध धाराओं में संतुलित सामंजस्य स्थापित करने का प्रयास किया है। इनके निबन्धों में इनकी आत्मा के मानवतावादी और सांस्कृतिक पक्ष को श्रेष्ठ अभिव्यक्ति प्राप्त हुई है। "शास्त्र और बुद्धि का समन्वय उनके निबन्धों की अन्यतम विशेषता है (वर्मा, 1969, पृ. 82)। परन्तु यह उल्लेखनीय है कि द्विवेदी जी के निबन्धों में व्यक्ति व्यंजकतावादी निबन्ध-कला का श्रेष्ठतम रूप देखने को मिलता है।

'समय और हम' और 'प्रश्न और प्रश्न' संकलनों में जैनेन्द्र कुमार ने समाज, अध्यात्म सम्बन्धी प्रश्नों के समाधान प्रस्तुत किए हैं। 'राष्ट्र और राज्य' में लेखक ने राष्ट्रिय जागरण और सांस्कृतिक नवोत्थान पर पांच क्रमबद्ध लेख प्रस्तुत किए हैं। इतस्तः और परिप्रेक्षा की रचनाओं को लेखक यद्यपि लेख की संज्ञा प्रदान करता है तथापि उनमें रोचक, आकर्षक और प्रेरक तत्त्व विद्यमान है। जैनेन्द्र जी ने मुख्यतः व्यास शैली का आधार ग्रहण किया है। इनके निबन्धों के सन्दर्भ में डॉ. प्रेम नारायण टंडन का विचार है कि जैनेन्द्र के ये निबन्ध जहाँ एक ओर वैचारिक गहनता के गुण से पूरित हैं, वहाँ भाषा की अस्पष्टता और दुरूहता भी देखी जा सकती है। वस्तुतः उनकी शैली में जो कुहासा व्याप्त है वह उनके चिन्तन का है, भाषा और शैली का नहीं। कुछ विशेष स्थलों पर चिन्तन की दुरूहता ने भाषा-शैली पर भी अपना आवरण डालना चाहा है परन्तु जैनेन्द्र इन निबन्धों में प्रायः स्पष्ट अभिव्यक्ति प्रदान कर गए हैं।
शांतिप्रिय द्विवेदी के 'चित्र और चिन्तन' संग्रह के प्रथम ग्यारह निबन्धों और 'स्मृतियॉ और कृतियाँ' संग्रह के स्मृतिखण्ड की सभी रचनाएँ संस्मरण और आत्म संर्मरण के रूप में व्यक्त हुई हैं। 'चित्र और चिन्तन' के निबन्धों में उन्होंने उपन्यास शैली के अनुरूप विमल और कमल की जीवनी प्रस्तुत करते हुए आत्मकथा के विविध खण्ड चित्रों को सजाया है। 'स्मृतियाँ और कृतियाँ' संकलन में मुख्य रूप से पुस्तक समीक्षाओं को ही संकलित किया गया है। इस वर्ग की रचनाओं में हजारी प्रसाद द्विवेदी कृत 'हिन्दी साहित्य' की समीक्षा उल्लेखनीय है। सर्वप्रथम उन्होंने उक्त कृति के कवर पेज पर लगी छोटी-सी चिट की ओर ध्यान आकृष्ट किया है,जिस पर लिखा है। 'इसके संक्षेप और कुग्जी का अधिकार प्रकाशक तथा लेखक का स्वाधिकृत्य है, अतः कोई भी व्यक्ति इसकी कुग्जी अथवा संक्षिप्त संस्करण प्रकाशित न करे।' इस उक्ति के आधार पर उन्होंने इसे परीक्षोपयोगी पुस्तक स्वीकार किया है" (वर्मा, 1969, पृ. 62)। साहित्यिक कृतियों के अतिरिक्त द्विवेदी जी ने साहित्यकारों की प्रवृत्तियों का स्वतंत्र विवेचन भी प्रस्तुत किया है। इस दृष्टि से उनकी निम्नलिखित रचनाऍ उल्लेखनीय हैं- 'परिक्रमा' में 'कालिदास की कला-सृष्टि', 'समष्टि के स्वर साधक रवीन्द्र' और 'कुसुम सुकुमार कवि पंत', 'स्मृतियाँ और कृतियाँ' में 'निराला जी : मेरी दृष्टि में', 'निराला जी : जीवन और काव्य', 'प्रेम और वात्सल्य के अजस्त्र कवि माखनलाल', 'राष्ट्रकवि गुप्तजी काव्य योग' आदि। इन निबन्धों में द्विवेदी जी ने रचनाकार के साथ तादात्म्य स्थापित करके सहद्दयतापूर्वक उनके साहित्य का 
विश्लेषण-मूल्यांकन किया है। उदाहरणार्थ 'निराला जी : मेरी दृष्टि में' शीर्षक निबन्ध का यह अंश द्रष्टव्य है, "काव्य की तरह ही निराला जी के स्वभाव में भी एक मुक्त छन्द है (द्विवेदी, 1966, पृ. 31)।" इनके निबन्धों में व्यास शैली का बाहुल्य है तथा अनेक स्थलों पर उदाहरण शेली के प्रयोग भी परिलक्षित होते हैं। वाक्य संरचना की दृष्टि से शान्तिप्रिय द्विवेदी जी की भाषा में यद्यपि तत्सम, तद्भव, अंग्रेजी, उर्दू और ग्रामीण बोली के शब्दों का प्रयोग परिलक्षित होता है तथापि उन्होंने अधिकतर तत्सम और तद्भव शब्दों का ही प्रयोग किया है। परन्तु उनकी भाषा क्लिष्ट या दुरूह नहीं है। संक्षेप में, "उनकी प्रभाववादी समीक्षा शैली में विचार की अपेक्षा राग-तत्त्व पर अधिक बल दृष्टिगत होता है" (वर्मा, 1969, पृ. 71)।

सामाजिक विषयों पर निबन्ध रचना के संदर्भ में बाबू गुलाबराय की समन्वयात्मक प्रतिभा के नैतिक और सांस्कृतिक पक्ष विशेष रूप से व्यक्त हुए हैं। 'प्राचीन की आधारशिला पर ही नवीन के भव्य-भवन का निर्माण' लेखक का अभीष्ट है। अतः इन निबन्धों में भारत के संविधान के अनुकूल किसी एक धर्म के प्रति आग्रह के स्थान पर निबन्धकार को भारतीय संस्कृति उसकी समग्रता में प्रिय है। गुलाबराय जी के राजनीतिक निबन्धों के अनुशीलन से यह स्पष्ट हो जाता है कि सक्रिय राजनीति से सर्वथा असम्बद्ध होते हुए भी उन्होंने स्वतंत्र भारत के विभिन्न सामयिक प्रश्नों का गम्भीरता से विशद विवेचन किया है। वे स्वतंत्र राष्ट्र के प्रति गर्व की भावना रखते हुए उसके उत्थान में प्रसन्न और अवनति में दुखी हुए हैं। इस दृष्टि से 'राष्ट्रीयता' और 'मेरे निबन्ध' के अनेक निबन्ध उल्लेखनीय है। इन्होंने शुद्ध मनोविज्ञान के सिद्धान्तों पर आधारित निबन्धों के अतिरिक्त मनोविज्ञान के सिद्धान्तों से पुष्ट निबन्धों की भी रचना की है। प्रथम वर्ग के निबन्धों में उन्होंने सिद्धान्त और व्यवहार दोनों पक्षों के सन्तुलन विवेचन के लिए एक ओर साहित्यिक उद्धरणों का आश्रय लिया है और दूसरी ओर लालित्य के लिए आत्मीय संवेगों को स्थान दिया है। इन्होंने मनोविज्ञान के सिद्धान्तों से पुष्ट निबन्धों में सिद्धान्त-विवेचन के स्थान पर मानवीय प्रवृत्तियों का आलेखन भी साहित्य मनोविज्ञान के सन्दर्भों के आधार पर किया है। गुलाबराय जी के व्यावहारिक समीक्षात्मक निबन्धों को तीन वर्गों में विभक्त किया जा सकता है- (1) रचना सम्बन्धी (2) साहित्यकार अथवा प्रवृत्ति सम्बन्धी (3) युगीन समस्या सम्बन्धी। इस वर्ग के निबन्धों के परिशीलन से उनकी समीक्षा पद्धति सौष्ठववादी दृष्टिकोण के अधिक समीप प्रतीत होती है। देशकाल की परिरिथियों के संदर्भ में लेखक अथवा रचना का तटस्थ किन्तु सहृदयपूर्ण निरीक्षण और यथास्थान
तार्किक एवं दार्शनिक चिन्तन उनकी समीक्षा की विशेषता है।

शिल्प की दृष्टि से माखनलाल चतुर्वेदी जी के निबन्ध अन्य गद्यकारों के निबन्धों से भिन्न हैं। गद्य काव्य के बिम्बों और प्रतीकों का आश्रय उनकी प्रमुख विशेषता है, किन्तु उन्होंने जिस स्वछन्दतावादी दृष्टिकोण और भाषा की सरसता पर बल दिया है वह कहीं-कहीं विचार धरातल पर आकर अपना वांछित प्रभाव खो बेठती है। कहीं सांकेतिक विश्लेषण के आधार पर सन्दर्भ सूत्र ग्रहण करने होते हैं और कहीं-कहीं बिम्बों की उलझन में विचार दब जाते हैं। चिन्तन की गहनता और लाक्षणिकता प्रभाव प्रस्तुत करने के प्रयत्न में आवरण युक्त हो जाती है। और निबन्धों का पाठक भाषा की स्निग्धता, अनुभूति की विशदता, चिन्तन की गहनता और भावात्मकता में अभिधेय अर्थ में भटक जाता है। इनके निबन्धों में लाक्षणिकता, सांकेतिकता और वक्रोक्ति के कारण जो कुहासा-सा छा गया है, उसे प्रशंसनीय नहीं कहा जा सकता। तथापि सामाजिक विचारात्मक निबन्धों के सर्जनात्मक लालित्य को पाठकों के तादात्मय-भाव को प्रश्रय प्रदान करने के कारण निबन्ध को शैली की दृष्टि से उपलब्धि ही कहा जाएगा। माखनलाल चतुर्वेदी जी के निबन्धों में व्यास शैली की प्रमुखता परिलक्षित होती है, परन्तु भावात्मक और संस्मरणात्मक निबन्धों में धारा शैली का भी प्रयोग हुआ है। इनके निबन्धों में समास शैली का प्रायः अभाव है, तथापि विभिन्न स्थलों पर व्यास और समास शेली के गठन के परिचायक सूत्र-वाक्य अवश्य प्रयुक्त हुए हैं। इनके सामाजिक और साहित्यिक निबन्धों में प्रायः स्पष्ट और स्वच्छ बिम्बों का प्रयोग किया गया है।

"रचना प्रक्रिया की दृष्टि से पं.विद्यानिवास मिश्र जी के निबन्ध सरस चिन्तन-क्रम प्रस्तुत करते हैं" (वर्मा, 1969, पृ. 126)। डॉ. दयाकृष्ण विजयवर्गीय 'विजय' के निबन्ध गंभीर साहित्यिक और सांस्कृतिक विषयों को सहेजे हैं। सभी निबन्धों में सोच की मौलिकता तथा विषय को व्याख्यायित करने की प्रशक्त ललक दिखाई देती है। ये सतही निबन्ध न होकर विषय को गहराई तक जाकर परखने वाले हैं तथा कथन की भंगिमा के साथ संवेदना जनित वस्तु को ऊँचाई प्रदान करने वाले हैं। समकालीन शब्दों को भी आपके निबन्धों ने स्थान-स्थान पर व्याख्यायित कर, वाम लेखकों की मान्यताओं को नकार, नवीन शब्दार्थ के साथ युग संदर्भों के साथ जोड़कर देखा है। इसी कारण निबन्धों के विषय आज के ज्वलंत प्रश्नों को विशेषकर साहित्यिक, सांस्कृतिक, सामाजिक, राजनीतिक तथा आर्थिक प्रश्नों को सहेजे हैं। व्यक्तित्व शोध समीक्षात्मक निबन्धों में 'महाप्राण निराला की सांस्कृतिक-राष्ट्रीय संचेतना?', 'प्रगतिशील भारतीयता के 
प्रगायक : राष्ट्रकवि मैथिलीशरण गुप्त', 'भक्तिमती मीरा का जीवन दर्शन', 'राजस्थान के शलाका पुरूष : भाईजी जन्मशती वर्ष में एक स्मरण', 'गुप्त जी की युगचेतना', 'पं. गिरिधर शर्मा नवरत्न की युग-चेतना', 'सूर का मानववाद', 'ढोला मारू रा दूहा में शृंगार विवेचन', 'विसलदेव रासो में विप्रलम्भ', 'वेलि क्रिसन रूख्मिणी री में शृंगार निरूपण' आदि उल्लेखनीय है। राजस्थान से सम्बन्धित आपके निबन्धों में 'हड़ोती अग्चल की साहित्यिक परम्परा', 'राजस्थान की लोक भाषाएँ', 'राजस्थान की संत परम्परा और रामस्नेही स्वामी रामचरण', 'राजस्थानी भाषा की एकरूपता की आवश्यकता', 'राजस्थान की साठोत्तरी नई कविता में प्रतीक एवं बिम्ब विधान', 'राजस्थानी काव्य में शृंगार भावना का विकास', आदि प्रमुख हैं। आपके अन्य निबन्धों के विषय-क्षेत्र- परम्परा की आधुनिकता, समय का साहित्य, सांस्कृतिक संकट, लोक विश्वास, साहित्यिक, पुनर्जागरण, आस्था और परिवर्तनकामिता, स्वतंत्रता संग्राम, संस्कृति, विधि क्षेत्र में हिन्दी, राजस्थानी भाषा, विश्वशान्ति, कुवैत (देश), साहित्यिक समारोह, दलित साहित्य, हादसा, मृत्यु का दार्शनिक रूप, स्वतंत्रता दिवस, महिला साहित्यकार, पत्रकारिता, पुरस्कार, शिक्षा प्रणाली आदि रहा है।

विश्वनाथ अय्यर के ललित निबन्धों में केरल की महक मिलती है। यात्रा का प्रसाद इनमें सुलभ है। भारतीय संस्कृति की झांकी इनमें है। सरसता और मुहावरेदार भाषा इनकी कलागत विशेषताएँ हैं। भोपाल के भारत भवन द्वारा आयोजित कवि-संध्या के निमित्त उनकी जो यात्रा प्रसिद्ध मलयालम कवि ओ.एन.बी.कुरूप के साथ हुई उसका रोचक विवरण 'कवि के साथ कवि नगरी को' तथा 'कालिदास की नगरी में' शीर्षक रचना में प्रस्तुत किया गया है। 'राग अमृत वार्षिकी', केरल की माँ अमृतानन्दमयी के प्रति भक्तिभावना से ओतप्रोत विवरण है जिनके आश्रम से धार्मिक, नैतिक प्रवचन के अतिरिक्त दीन दु:खियों की परिचर्या होती है। हिन्दी दिवस पर केन्द्रीय हिन्दी संस्थान द्वारा अनेक साहित्यकारों के साथ डॉ० अय्यर को राहुल सांकृत्यायन पुरस्कार प्राप्ति का विवरण है- 'संत समागम तीरथराजू'। 'सीढ़ी और सांप' दैनिक व्यावहारिक जीवन में अप्रत्याशित हानि और लाभ की सामान्य चर्चा से पूर्ण है। 'पद्मनाभ प्रभु फणि पर शायी' में तिरूअनन्तपुरम के प्रसिद्ध श्री पद्मनाभ मन्दिर के पुराण, इतिहास, कला एवं संस्कृति का प्रामाणिक परिचय है। कला और सथापत्य के लिए प्रसिद्ध केरल के महल और मंदिर-निर्माण की प्राचीन शैली का विवरण 'घने केर-तरू तले' में मिलता है। 'चलो लौहतीर्थ' में भिलाई इस्पात कारखाने का विवरण है। तमिल-मूल और मलयालम भाषी होने के नाते लेखक ने तमिल और मलयालम संस्कृ
ति-साहित्य-इतिहास-कला के श्रेष्ठ अंशों से हिन्दी पाठक को परिचित कराया है,सुबोध गम्य भाषा एवं रोचक शैली में। इन्होंने काव्य पंक्तियों के माध्यम से निबन्ध की अभिव्यक्ति की है, "माँ के विषय में कहने की बड़ी इच्छा हो रही है। पर तुलसीदास की पंक्ति ही र्मरण आती है- गिरा अनयन नयन बिनु बानी" (अय्यर, 1996, पृ. 17)। अलंकारिक वाक्यों का प्रयोग हुआ है- "आप दुबारा-तीसरी बार, चौथी बार बराबर माँ के दर्शन के लिए जाते हैं। माता आपको पहचान लेती है। जैसे गाय सैकड़ों बछड़ों की भीड़ में भी अपने बछड़े को पहचानती है। रंभाहट से बछड़ा भी माँ को पहचानता है" (अय्यर, 1996, पृ. 22)। आपके निबन्धों में मुहावरों/लोकोक्तियों का समावेश परिलक्षित होता है, "भतृहरि के एक छन्द का अर्थ है कि जब मैं किंचिज्ञ था बहुत उथली बातें जानता था - तब थोथा चना बाजे घना की दशा में था। उस समय मैं मदजल से मस्त हाथी सा मदान्ध रहा। सोचता था कि मेरे समान कोई नहीं। मगर जब यथार्थ विद्वानों की संगति में आने लगा तभी कुछ-कुछ समझने लगा। तभी पता लगा कि मैं कितना कम जानता हूँ। इसी को हिन्दी कहावत में 'अधजल गगरी छलकत जात' कहते हैं" (अय्यर, 1996, पृ. 47)। उपरोक्त उद्धरण में निबन्ध की 'व्यक्तित्व की प्रधानता' विशेषता की पूर्ति होती है। एक अन्य निबन्ध में कहावत का यह समावेश द्रष्टव्य है, "कहावत है, घर का भेदी लंका ढाहे। कई सज्जन बनती हुई बात को बिगाड़ने में बड़ा मजा पाते हैं" (अय्यर, 1996, पृ. 23)। आपके निबन्धों में चिन्तन परक विशेषताओं की झलक मिलती है, "महापण्डित राहुल सांकृत्यायन के प्रति श्रद्धा सूचित करने संस्थान का स्थापित पुरस्कार राष्ट्रपति के कर कमलों से मुझे भरी सभा में प्राप्त हुआ। कैमरे की कई बत्तियॉ मेरे चेहरे पर पड़ीं तो कुछ पुलकित अवश्य हुआ। मगर कोलाहल थमने के बाद एकांत में सोचने लगा कि राहुल सांकृत्यायन की चरण धूलि के लायक होने के लिए मुझे जाने कितने जन्म लेने पड़ेंगे" (अय्यर, 1996, पृ. 45)। चिन्तनपरक, व्यक्तित्व की प्रधानता उद्धरणों में यह अंश भी दर्शनीय है, "मैं बारम्बार आदमी के इस व्यवहार पर सोचता हूँ कि वह खुद सीढ़ियाँ चढ़ना चाहता है और प्रतियोगी को साँप के मुँह में फँसते देखना" (अय्यर, 1996, पृ. 34)। आचार्य निशांतकेतु जी के तीन निबन्ध-संग्रह प्रकाशित हैं एवं उनके निबन्धों में विषयगत विचार-गाम्भीर्य एवं चिन्तन-अनुचिन्तन का वृहत् आयाम है।

\section{व्यंग्य निबन्ध}

हजारी प्रसाद द्विवेदी के व्यंग्य निबन्धों में वचन वैदग्य इस प्रकार है कि 'आज है इस निरूपाय निरन्न निर्वाक मूढ़ 
जनता की बेतुकी भीड़ जो जीते हैं, इसलिए कि मौत नहीं आ जाती; और मरते हैं, इसलिए कि जीने का कोई रास्ता नहीं। इन्होंने अपने व्यंग्य निबन्धों में प्रतीक, उपमानों का खुलकर प्रयोग किया है- 'मुझे इनको देखकर इन नेताओं की बात याद आती है, जो किसी प्रकार जमाने का रूख नहीं पहचानते और जब तक नई पौध के लोग उन्हें धक्का मार नहीं देते, तब तक जमे रहते हैं। 'एक साथ किसी उद्धरण में कई विषयों पर व्यंग्य का प्रहार करने में आचार्य द्विवेदी जी के निबन्ध का विशेष महत्त्व है- 'धरती और आसमान में कुछ साँठ-गाँठ है। शायद हमेशा ही रहा है यहाँ भी लोग कहते हैं कि अन्न की कमी नहीं है पर मिल नहीं रहा है। राशन की दुकानें खाली है, चोर बाजार भरे हैं-सब है, सिर पर से उड़ रहा है-केवल मिलता नहीं है। अखबारों में पढ़ता हूँ, अच्छी व्यवस्था होने जा रही है, आँखें देखती हैं, हो नहीं पा रही है।'

जैनेन्द्र कुमार के "सामाजिक विचारात्मक निबन्धों का प्रणयन प्रमुख रूप से 'इतस्ततः' की स्फुट रचनाओं में हुआ है जिसमें लेखक ने अपने स्त्री-पुरूष सम्बन्ध विषयक विचारों को कलात्मक शैली में स्पष्ट किया है। लेखक विवाह और प्रेम को दो समानान्तर रेखाओं में चलते हुए देखना चाहता है। इसके दूषित पक्ष का चित्रण करते हुए लेखक ने पुरूष जाति के व्यभिचारों पर कटु व्यंग्य प्रस्तुत किए हैं। जो धर्म में तो सती धर्म चाहते हैं और बाहर उन्हें ऐसी स्त्रियों की आवश्यकता होती है जो पत्नी न हो" (कुमार, 1962, पृ. 32)। विभिन्न स्थलों पर व्यास और समास शैली का मिश्रण प्रस्तुत हुआ है। यथा, "हमारी मर्यादा का तकाजा है कि प्रेम और विवाह दो समानान्तर रेखाओं से चलें" (कुमार, 1962, पृ. 32)। शान्तिप्रिय द्विवेदी ने अपने निबन्ध 'चित्र और चिन्तन' 1964 में अपने जीवन के अभावगत चित्रों को स्मृति में संजोते हुए सामाजिक और आर्थिक क्षेत्रों की विसंगतियों पर व्यंग्य प्रस्तुत किए हैं" (द्विवेदी, 1964, पृ. 7)। वैसे बाबू गुलाबराय जी ने "हास्य की हर रोज होली और ज्ञान की हर रात दिवाली" जैसी उक्तियों से यह प्रकट किया है कि एक ओर हास्य का लालित्य और दूसरी ओर विचारात्मकता का समावेश निबन्ध की अन्यतम विशेषता है (गुलाबराय, 1962, पृ. 148)। पंडित माखनलाल चतुर्वेदी को प्रतीक और अन्योक्तियों के माध्यम से अपनी बात कहना या लेख प्रस्तुत करना अधिक प्रीतिकर लगता है। शब्द सम्पदा की दृष्टि से उन्होंने अपने निबन्धों में विविध भाषाओं के शब्दों को ग्रहण किया है।' 'मैंने सिल पहुँचाई' के निबन्ध 'पत्र इण्टेलेक्चुअल' में विद्यानिवास मिश्र ने पत्र के माध्यम से कलात्मक भावपूर्ण शैली में परम्परा और आधुनिकता पर मधुर व्यंग्य प्रस्तुत किया है" (वर्मा, 1996, पृ. 126)। पण्डित विद्यानिवास मिश्र
के व्यंग्य निबन्धों में वचन वैदग्य इस प्रकार है, "जिन्हें अपने बाप का पैर छूने में हिचक होती है वे अपने अफसर के या मंत्री के पैर छूने का अवसर पाने में ही अपने को बहुत गौरवान्वित मानते हैं" (मिश्र, 1962, पृ. 67)।

डॉ. दयाकृष्ण विजयवर्गीय 'विजय' के व्यंग्य भी यथार्थ के धरातल पर तो अवश्य अवस्थित हैं,पर तर्क एवं विचार के अधिष्ठान पर खड़े हैं। आपके पहले संग्रह 'साहित्य संस्कृति और युगबोध' 2000 के भाग-दो 'प्रसंगवश' में व्यंग्य निबन्ध की अधिकता है। ये निबन्ध 1990 से 1993 के बीच के हैं। आपने दलित साहित्य, शोक दिवस मनाने, रक्षाबन्धन के नये आयाम, पुरस्कार के पीछे भागमभाग, कवि सम्मेलनों के बढ़ते रूप, शिक्षा शास्त्रियों के ढपोरशंख आदि पर व्यंग्यार्थ प्रस्तुत किया है। डॉ.रामप्रसाद मिश्र के 'मौर्ख्य शास्त्र' जो कि पाँच निबन्धों का व्यंग्य प्रबंध है एवं 'जी हाँ, यह दिल्ली है' दोनों व्यंग्य संग्रह हैं-वर्तमान में अनुपलब्ध है। इनके सार भाग 'हास्य का इन्द्रधनुष', 'मौख्य्य और साहित्य', 'संसार के मूखों एक हो!' ग्रन्थों में प्राप्त है। आपने भ्रष्टाचार, जन पाखण्ड, नेतृपाखण्ड, बौद्धिक व्यभिचार प्रवृति का विराट समावेश किया है। बौद्धिकता, निस्संगता एवं भाषा स्तर आपके साहित्य की प्रमुख विशेषता है। आपके व्यंग्य साहित्य जिसमें बड़ी संख्या में निबन्ध विद्यमान हैं, न दलगत व्यंग्य हैं, न अखबारी व्यंग्य, न अर्थलाभ व्यंग्य। आपने नव्यतम समस्याओं को नव्यतम आयामों में उठाया है, आपके व्यंग्य बौद्धिकता एवं तार्किकता से प्रेरित है। आपके व्यंग्य की चित्रण-शेली भिन्न है, दृष्टिकोण 'बद्ध' न होकर 'मुक्त' है।

आचार्य निशांतकेतु के ललित निबन्ध संकलन 'ललित लेख' (1986) 30 ललित निबन्धों का संग्रह है जिसमें विशेषकर निंदा-रस निबन्ध व्यंग्य है। आपके दूसरे निबन्ध संग्रह 'ललित चिन्तन (1993) में अनेक स्थलों पर सामाजिक विकृतियों और विडम्बनाओं तथा विद्रूपता और विपथगामिता पर गहरा व्यंग्य है। आपके अन्य निबन्ध संग्रह 'समसामयिक निबन्ध' (2001) में अस्सी निबन्ध समाहित हैं एवं अनेक स्थलों पर व्यंग्य स्पर्श हैं। आचार्य निशांत केतु जी की मान्यता है, जो काम अनुनय-विनय अथवा आक्रोश से साधित नहीं होता, वह व्यंग्य से हो जाता है। एक आम आदमी और कुछ नहीं तो चिढ़ा तो सकता है। कबीर के हाथ में अपने तद्युगीन समाज के लिए अन्य कोई सुधारात्मक उपाय तो नहीं था,किन्तु चिढ़ाने की कला उन्हें सिद्धहस्त थी। उन्होंने ऐसा चिढ़ाया और इतना चिढ़ाया कि कबीर शिखर पर चढ़ गए और विडम्बना और विद्रूपता करने वाले लोग तलहटी में इस तरह छटपटाते रहे, जैसे देह का विभाजन रुण्ड और मुण्ड में हो गया है। व्यंग्य में बाण की 
तीब्रता और चुभन होती है, जो हास्य में सम्भव नहीं है। डॉ. एन. ई. विश्वनाथ अय्यर के निबन्ध संग्रह 'सीढ़ी और सांप'(1996) में हलकी-फूलकी व्यंग्यात्मक शैली में 'किस्सा कुरसियों का' लिखा गया है, जिसमें कुर्सी के आधुनिक विभिन्न अर्थ और आशयों का उल्लेख है, पद की गरिमा से लेकर पद लोलुपता तक का। कुछ उद्धरण प्रस्तुत हैं, "कार्यालय के भीतर किसी अफसर के सीनियर होने का पता बिना पूछे उसकी कुर्सी बताएगी। अफसर यदि केश राशि के हों, तो सिर टिकाने की जगह तेल से चिकनी व पुरानी लगती है। बैठक पर पुराना गद्दा। अगर पान खाने वाले बाबू हों तो मेज के पायों पर चूने के निशान" (अय्यर, 1996, पृ. 34)। कुर्सियों की गन्दगी की गाथा पर यह अंश द्रष्टव्य है, "अस्पताल और थियेटर लोक सेवा के संस्थान हैं। पहला शारीरिक कष्ट से छुड़ाता है तो दूसरा मानसिक तनाव से। किन्तु इन दोनों की बेचारी कुर्सियाँ बदनाम हैं। यहाँ पता नहीं, अशरीरी पोशाक में छोटी-सी टुकड़ी बनकर खटमल आकर कुर्सियों में समा जाते हैं। लोगों के पसीने से ये बढ़ते हैं। आगन्तुकों की जानकारी के बिना ही उनकी जाँघ, चूतड़,हाथ सब जगह का खून पीकर बड़े स्वस्थ हो जाते हैं" (अय्यर, 1996, पृ. 34)। वचन वैदग्य का पुट भी मिलता है, "सरकारी सेवा वाले लम्बी छुट्टी लेने से कतराते हैं क्योंकि लौटने पर पुरानी कुर्सी नहीं मिलती" (अय्यर, 1996, पृ. 35)। डॉ. अय्यर ने अपने व्यंग्य में मानवीकरण का प्रयोग किया है, "एक दिन रात को अपनी कुर्सी को कुछ फुसफुसाते सुना। पूछा-'मेरे आश्रयदाता! आदेश दीजिए।' उसने कहा-तुम मेरा 'गोत्रयान' क्यों नहीं लिखते? मैंने निवेदन किया कि गोत्रयान लिखने की क्षमता मुझमें नहीं; मगर आपके वंशजों का स्तोत्रगान कर सकता हूँ" (अय्यर, 1996, पृ. 30, 31)। डॉ. अय्यर के निबन्धों में उद्धरण शैली में व्यंग्य का दर्शन होता है। धर्म के नाम पर डींग मारने वालों पर इन्होंने व्यंग्य किया है, "एक अस्पताल के दो वार्डों में रोग बढ़ने से दर्द के मारे दो रोगी तड़प रहे थे। उनके बन्धु उनके लिए दवा लेकर आ रहे थे। एक बंधु को दक्खिनी तरफ के वार्ड में जाना था, दूसरे को उत्तरी तरफ के। गलियारे में एक ऐसे द्वार पर वे मिले जिससे एक ही व्यक्ति जा सकता था। दोनों हठ करते रहे कि मैं ही पहले जाऊँगा। उधर रोगी दर्द से तड़प रहे थे। अपने धर्म की श्रेष्ठता के नाम पर डींग मारने, झगड़ा करने वाले इसी तरह के होते हैं“ (अय्यर, 1996, पृ. 20)। अन्य उद्धरण में नशापान से जनित शारीरिक व आर्थिक अपव्ययता को दर्शाया गया है, "एक भवन के एक कमरे में एक कैंसर रोगी है। वह दर्द के मारे चिल्लाता रहता है। दर्द को कम करने वाली दवा खरीदने उसके पास पैसे नहीं। बगल वाले कमरे में दूसरा व्यक्ति है। वह
शराब,हेरोयिन का सेवन करता, स्त्रियों के साथ रंगरेलियों में अपना सर्वस्व लूटा रहा है। वह अपने सर्वनाश के लिए जितना पैसा बर्बाद करता है उसका एक हिस्सा कैंसर रोगी का दर्द दूर कर सकता है। फालतू चीजों पर पैसे लूटाने वाले दूसरों की मदद करें तो वे खूद सर्वनाश से बचेंगे। दूसरों की भलाई भी होगी" (अय्यर, 1996, पृ. 20)। पौराणिक सन्दर्भों का इन्होंने उचित प्रयोग किया है, "इसलिए रामचरितमानस के परशुराम की तरह अपने गुण आप ही सुनाता हूँ"' (अय्यर, 1996, पृ. 65)।

\section{निष्कर्ष}

निष्कर्षतः विद्वान लेखकों की संदर्भगत धारणा इस प्रकार हैं। डॉ. एन. ई. विश्वनाथ अय्यर के चौथा संकलन 'सीढ़ी और सांप' की भूमिका लिखते हुए डॉ. कृष्णचन्द्र गुप्त जी ने लिखा है - 'सामान्य तथा विशिष्ट पाठक भी निबन्ध पढ़ने से बचता है - गम्भीरता व तार्किकता के अनावश्यक बोझ के कारण। आचार्य निशांतकेतु जी की मान्यता है कि जो काम अनुनय-विनय अथवा आक्रोश से साधित नहीं होता, वह व्यंग्य से हो जाता है। डॉ. रामप्रसाद मिश्र का मत है कि आज का अधिकांश 'चर्चित' साहित्य 'बद्ध' है 'मुक्त' नहीं; और, व्यंग्य निबन्ध अपवाद नहीं। डॉ. दयाकृष्ण विजयवर्गीय 'विजय' का विचार है कि समकालीन व्यंग्य निबन्ध का चिन्तन वायवी है। उनका धरातल सतही है। उनमें गहराई का अभाव है। औदात्य तो उन्हें छू तक नहीं गया है। ज्ञानेन्द्र वर्मा की मान्यता है कि कलात्मक अभिव्यक्ति प्रदान करने में निबन्धकार प्रायः मूल विषय से संदर्भ खो बैठते हैं। गोविन्द मिश्र जी ने लिखा है कि निबन्ध, बात को सीधा रखते हैं और भावाकुलता अधिक है। हँसने या मजाक उड़ाने के बजाय निबन्धों में पीड़ा और दुःख का स्वर मुख्य है। सन्दर्भगत डॉ. एन. पी. कुट्टनपिल्ले की धारणा है कि निबन्ध उच्च स्तरीय वैचारिकता, प्रौढ़ चिन्तन एवं रोचक विश्लेषण शैली से अलंकृत होने चाहिए। डॉ. हरीश नवल ने लिखा है कि 'व्यंग्य एक कठिन विधा है। जन करूणा का पारावार जमा हो जाता है तब व्यंग्य फूटता है। व्यंग्य पढ़कर यदि कुछ कचोटें, कुछ भारीपन लगे, कहीं मन में विरोध की लहर उठे तथा स्थिति की त्रासदी पाठक को समझ आए - मेरा व्यंग्यकार संतुष्ट होता है। कान्तिलाल ठाकरे ने व्यंग्य को दिशा दर्शक व जीवन दर्शन से भरपूर बताया है। विनोद साव जी सरल भाषा में आम आदमी की कुण्ठाओं को उघाड़ने की बात कहते हैं। डॉ. शिव शर्मा के अनुसार, व्यंग्य लिखने के लिए सन्यास लेकर किसी आश्रम में जाने की आवश्यकता नहीं होती। जब तक समाज में विसंगतियाँ, अन्याय, अत्याचार, असमानता है तब तक व्यंग्य की फसलें 
लहलहाती रहेंगी। सुधीर ओखदे व्यंग्य लेखन को मजबूरी नहीं कर्त्तव्य मानते हैं। विसंगतियों से आँख चुराकर चुप नहीं बैठने वालों की कलम से व्यंग्यकार की हैसियत से समाज सेवा टपकती है।

रमेश टण्डन, पी-एच. डी., सहायक प्राध्यापक (हिन्दी), महात्मा गांधी शासकीय कला एवं विज्ञान महाविद्यालय, खरसिया (छ.ग.), भारत।

\section{संदर्भ सूची}

अय्यर, एन. ई. विश्वनाथ (1996). सीढ़ी और सांप (पृ. 17, 22, 47, $23,45,34,35,30-31,20,65$ )/ तिरूवनन्तपुरम् : स्वाति प्रकाशन।
कुमार, जैनेन्द्र (1962). इतस्ततः (पृ. 32)/ नई दिल्ली : पूर्वोदय प्रकाशन।

द्विवेदी, शान्तिप्रिय (1966). स्मृतियाँ और कृतियाँ (प्र. 31)/ वाराणसी : विद्याभवन प्रकाशन।

द्विवेदी, शान्तिप्रिय (1964). चित्र और चिन्तन (पृ. 7)/ वाराणसी : विद्याभवन प्रकाशन।

गुलाबराय (1962). जीवन रश्मियाँ (पृ. 148)/ दिल्ली : वाणी प्रकाशन।

मिश्र, विद्यानिवास (1962). आंगन का पंछी और बनजारा मन (पृ. 67)। दिल्ली : वाणी प्रकाशन।

वर्मा, ज्ञानेंद्र (1969). समसामयिक हिन्दी निबन्ध (पृ. 82, 62, 71, 126)/ दिल्ली : ज्ञान भारती प्रकाशन। 